\title{
BIJGELOOF IN DE PREANGER-REGENTSCHAPPEN
}

DOOR

J. H A B B E M A.

Hetgeen hieronder volgt is een overzicht van bijgeloovige gebruiken bij het bouwen en bewonen van huizen in de PreangerRegentschappen, waarmee, als ze niet in strijd zijn met plaatselijke verordeningen en de toepassing er van niet tot belangrijke vermeerdering van uitgaven zou leiden, zooveel mogelijk rekening wordt gehouden. Is dat om de evenvermelde of andere redenen niet geschied, dan is men dadelijk gereed om ziekte of ongeval daaraan toe te schrijven. Het gaat daarmee als met het bijgeloof onder ons, Europeanen. Als een schip vergaat en men komt tot de ontdekking dat het op een Vrijdag was uitgezeild, dan wordt het ongeluk aan die omstandigheid toegeschreven en zal dat als een nieuw bewijs worden aangemerkt, dat de Vrijdag voor het uitzeilen van schepen een ongeluksdag is.

Natuurlijk geldt het medegedeelde niet onveranderd voor het geheele gewest; plaatselijke wijzigingen zijn talrijk.

Op volledigheid maakt dit artikel dan ook geen aanspraak. Het was er mij voornamelijk om te doen, eens te laten zien, hoezeer alle handelingen van den inlander worden beheerscht door voortdurende vrees voor de tallooze geesten, die, naar hij gelooft, overal aanwezig zijn.

Hoogst wenschelijk is het, dat er van dat onderwerp wat meer studie worde gemakkt, want het is onmogelijk het doen en laten van den inlander billijk te beoordeelen en bij het straffen van overtredingen en misdrijven rechtvaardig te zijn in den vollen zin van het woord, als men niet weet welke motieven van bijgeloovigen aard op zijne daden van invloed zijn geweest.

Zonder overdrijving kan men spreken van een juk waaronder de inlander door zijne vrees voor geesten en spoken gebukt gaat en het zou een weldaad zijn hem daarvan te bevrijden.

Het eenige middel om dat doel te bereiken en al die djoerig's 
en dĕdĕmit's op de vlucht te jagen, is degelijk ontwikkelend onderwijs. Voor kennis en ontwikkeling zal het bijgeloof, dat terecht altijd in één adem wordt genoemd met domheid en onkunde, moeten wijken. Dit laatste heeft veel van een oratio pro domo, maar is daarom niet minder waar.

De Soendasche tekst is op mijn verzoek opgesteld door den inlandschen onderwijzer Adrwisıstra te Bandoeng, naar gegevens hem door bejaarde inlanders verstrekt. Zijn opstel is daarna met verschillende personen besproken en voor zooveel noodig gewijzigd.

Ik heb gemeend ook den Soendaschen tekst te moeten meedeelen, omdat de litteratuur van die taal nog vrij beperkt en speciaal het genre "folklore" daarin slecht vertegenwoordigd is.

Door bij de vertaling elk woord zooveel mogelijk tot zijn recht te doen komen, hoop ik tevens de belangstelling te wekken van de beoefenaren van het Soendaasch.

De eijfers achter eenige woorden en uitdrukkingen in den tekst, waarvan er enkele niet voorkomen in de Woordenboeken van Oosting (O.) en Coolsma (C.) verwijzen naar de aanteekeningen hierachter. 


\section{Samemeh djadi imah.}

Lamoen oerang rek njijeun imah mimitina koedoe njadijakeun heula kai-kai anoe harade.

Dina hal milihna kai reja pisan pabidähan ${ }^{1}$ anoe kaloewangkeun.

Sapĕrkara kai pikeun bahan imah teh koedoe warna, sakoerangkoerangna koedoe aja 7 roepa, noeroetkeun powe toedjoeh, watĕkna ${ }^{2}$ matak rahajoe ka noe ngeusian.

Kadoewa, imah teh koedoe ditěrapan kai anoe haseum-haseum boewahna, kajaning, asĕm atawa hoeni, djeung kai noe seungit kĕmbangna, tjara kananga atawa tjampaka.

Noe tiheula watěkna matak oeroej anoe nendjo, tĕgĕsna matak kabita, lir noe njiram nendjo hoeni atawa asĕm. Noe pandeuri kasiatna ${ }^{3}$ kana imah, noengtoen kaseundeuhan koe tatamoe, matak bětah anoe ngandjang soemawonna anoe ngeusian.

Sabalikna pirang-pirang kai anoe teu hade dipake dangdanan imah. Sapĕrkara kai anoe tjoetjoekan tangkalna, kaja dadap tjangkring djeung lianna, eta hĕnteu hade dipake, karana matak roengsĕb ${ }^{4}$ pikirna anoe ngeusian, tĕgĕsna reja kasoesah.

Kadoewa kai roentoeh, ngarangrangan djeung noe poegoer, sabab tiloewanana matak teu awet oemoer atawa hese rĕdjĕki.

Katiloe kai noe oeroet imah kahoeroewan, eta ge teu hade dipake dangdanan imah, sabab matak kahoeroewan deui.

Kai anoe sangĕt, hade oge dipake dangdanan imah, tapi koedoe make sarat, 5 dipakoe koe pakoe ěmas atawa perak, malar djoerig noe aja dina eta kai njingkah tidinja from Brill.come4/26/2023 12:20:48AM 


\section{Vóordat het huis gebouwd is.}

Als ik een huis wil bouwen (maken) moet ik eerst goed hout bijeen brengen (klaar leggen).

$\mathrm{Bij}$ het kiezen van het hout worden zeer vele bijgeloovige gebruiken in acht genomen.

In de eerste plaats moet het hout voor den bouw van het huis bestemd (veel)soortig zijn, minstens moeten 7 soorten van hout (gebezigd worden), overeenstemmende met de 7 dagen (der week); het effect daarvan is, dat de bewoner voorspoed zal hebben (vrij blijven van leed en rampen).

In de tweede plaats moet er voor het huis hout gebezigd worden van boomen welke zure vruchten dragen, zooals van de tamarinde of boeniboom en van boomen waarvan de bloemen lekker rieken, zooals van de kananga of de tjampakaboom.

Van het eerste (nl. de keuze van asĕmhout enz.) is het effect, dat men watertandt bij het zien (van het huis) m. a. w. dat men er begeerig naar is, even als iemand die zich baadt en tamarinde of boenivruchten ziet.

Van het laatste is het effect op het huis, dat het leidt tot het voortdurend door gasten bezocht worden, en dat de bezoekers, maar vooral de bewoners, er zich "lekker" gevoelen.

Daarentegen zijn er vele houtsoorten, die niet geschikt zijn om voor materiaal bij den huizenbouw te dienen.

In de eerste plaats hout van boomen waarvan de stam stekels of doornen heeft, zooals de dadap tjangkring en andere, die zijn niet goed om gebruikt te worden, omdat daardoor de bewoners veel zorg, getob zullen hebben d. w. z. veel moeielijkheden zullen ondervinden.

In de tweede plaats, hout van omgevallen boomen, van (door ouderdom) bladerlooze boomen en van boomen welke den kruin hebben verloren, omdat (door het gebruik van) die drie soorten (de bewoners) niet lang zullen leven of moeielijk den kost zullen verdienen.

In de derde plaats, hout afkomstig van een verbrand huis, ook dat is niet goed om voor huizenmateriaal gebezigd te worden, omdat er dan weer brand zal ontstaan (in het nieuwe huis).

Hout van heilige (angkĕr) boomen, kan ook wel gebruikt worden, maar dan moet een middel worden toegepast, om te maken dat de geest die in den boom zit, van daar weggaat, en wordt deze ge- 
Ari ngamimitianana migawe, poepoes papas atawa koedak kadek, hĕnteu meunang sagawajah atawa salamangsa, ${ }^{6}$ koedoe dina wĕwĕdalan anoe rek boga niat, sapĕrti wěwĕdalanana dina powe Djoemaäh, eta koedoe di Djoeınaäh deui.

Tatapi sakitoe deui hĕnteu meunang singsing Djoemaäh koedoe milih noe hĕnteu mĕnĕran naãs atawa rarangan boelan.

Lĕmah anoe bakal diimahan, tangtoe beunang milih anoe hade, sakoerang-koerangna oelah anoe goreng teuing bae.

Dĕmi sĕpoeh-sĕpoeh nganggona lahan piimaheun, anoe kasĕbat sae, ijeu dihandap dipĕrtelakeun sawareh-wareheun.

1. Tanah anoe bahe ngetan ngaler, watĕkna ka noe tani matak moekti, ka noe dagang matak beunghar, djaoeh ti bantjang pakewoeh.

2. Tanah anoe bahe ngetan woengkoel, disěboet "anggon-anggon anoe tani", sabab watikna noengtoen resĕp pĕpĕlakan, toer hade djadina.

3. Tanah anoe bahe ngoelon disěboet "anggon-anggon pandita", sabab watĕkna mawa bageur ka noe ngeusian, ěmboeng latjoer, djĕleh maen djeung salianna ti eta sakoer lampah kagorengan.

4. Tanah noe kalioeng koe tjai, watěkna "tiis", teu aja panjerewedan.

5. Ari noe panghade-hadena tanah pilĕmboereun atawa pinagaraeun, nja eta lĕmah "ngagaloedra ngoepoek", 8 tĕgĕsna tjai tina tiloe madhab tjampoer ngotjor katěngah, toeloej palid kamadhab anoe kaopat, tjontona sapĕrti padataran tanah Bandoeng disĕboet "ngagaloedra ngoepoek", sabab tjai ti kaler, wetan djeung kidoel, ngotjor katĕngah, tjampoer di Tjitaroem, ari mitjeunua kasabeulah koelon.

Dĕmi tanah anoe goreng dilĕmboeranana nja eta:

1. Tanah noe kaoengkoelan koe djalan, ari peuntaseunana papak 
spijkerd met gouden of zilveren spijkers (worden gouden of zilveren spijkers in den boom geslagen).

Met het werken, nl. het hakken en bewerken (van het hout) mag geen aanvang worden gemaakt op elk willekeurig tijdstip, dat moet (geschieden) op den weekdag waarop de persoon die het voornemen heeft (het huis te bouwen), geboren is, b.v. als hij geboren is op een Vrijdag, dan moet ook op een Vrijdag worden begonnen.

Maar daarbij dient nog in acht genomen te worden, dat het niet kan op elken willekeurigen Vrijdag, men moet (een Vrijdag) kiezen, die niet valt op een ongeluksdag of in een verboden maand.

De grond waarop men het huis zal zetten, moet zonder mankeeren goed gekozen zijn, minstens (althans) mag de grond niet te slecht zijn.

Welke emplacementen voor een huis door oude menschen (of voorouders) gebezigd en goed genoemd worden, zal hieronder gedeeltelijk worden verklaard (medegedeeld).

$1^{\mathrm{e}}$ Grond die afloopt van het Oosten naar het Noorden, maakt dat landbouwers in goeden doen geraken en handelaren rijk worden, nooit verliezen lijden en bevrijd blijven van moeielijkheden.

$2^{e}$ Grond die slechts (d. w. z. recht) naar het Oosten afloopt, wordt grond voor landbouwers genoemd, omdat hij leidt tot lust in den landbouw en daarbij tot goede resultaten daarvan.

$3^{\mathrm{e}}$ Grond die naar het westen afloopt, wordt grond voor geestelijken genoemd, omdat deze de menschen die daarop wonen tot braafheid leidt, zij niet slecht (losbandig) willen worden en een afkeer hebben van spelen en alle andere verkeerde handelingen.

4. Grond die door water wordt omringd, is koud van aard, daarop komen geen twisten voor.

$5^{\text {e }}$ De beste grond voor een kampoeng of een nĕgĕri is grond (genaamd) "ngagaloedra ngoepoek", d. w. z. grond waarover van drie windstreken komend water naar het midden stroomt, dat vervolgens afloopt naar de vierde windstreek, zooals b.v. de vlakte van Bandoeng, die "ngagaloedra ngoepoek" genoemd wordt, omdat het water van het Noorden, het Oosten en het Zuiden naar het midden stroomt, zich vereenigt met de Tjitaroem en dan naar het Westen stroomt.

Gronden, die slecht zijn om daarop een huis (of een kampoeng) te bouwen of waarop men dat nooit doet, zijn :

$1^{\text {e }}$ Grond die door den weg gedomineerd wordt (die dus lager ligt 
djeung eta djalan, eta watěkna matak kaoengkoelan koe noe ti tonggoh. Oepama djĕlĕma anoe ngimahan tanah kitoe teh geus beunghar, tidinja dipeuntaseunana djalan teh aja noe ngimahan deui paeunteung-eunteung djeung noe di lĕgok teja, eta anoe di lĕgok teh sok djadi malarat atawa hilang, nja eta kaoengkoelan koe noe ti tonggoh.

2. "Lĕmah goenting, nja eta tanah noe katjapit koe djalan tjagak atawa koe tjai, watěkna sangar.

3. Tanah noe bahe ngetan ngidoel sabab ĕnja oge watěkna mawa daek kana pĕpĕlakan, tapi tara djadi.

4. Tanah anoe bahe ngoelon ngaler, disěboetna "anggon-anggon djaksa," watěkna loba panjerewedan.

5. Tanah anoe bahe ngoelon ngidoel, disěboet "anggon-anggon doerdjana," watĕkna sok kalindeukan ${ }^{9}$ bangsat.

6. Lĕmah "talaga ngĕmbĕng," tĕgĕsna tanah lĕgok, tjai ti madhab papat ngotjorna koempoel ka tĕngah, tapi taja pamitjeunanana, ngĕmbĕng 10 bae, eta pĕrbawana, tara djadi djoewal meuli.

7. Lĕmah "kantjah nangkoeb", nja eta anoe tjara kantjah ditangkoebkeun, eta watĕkna panas, teu bisa ngampihan rĕdjĕki. Ijeu anoe doewa pangpandeurina disěboet panggoreng-gorengna, meh tara aja noe ngeusian.

Tanah piimaheun teja hĕnteu kalis koe beunang milih, koedoe bae make ditoembal deui. Babakoena pisan anoe sarat koedoe ditoembal heula teh, nja eta tanah anoe kakara diimahanana. Dĕmi sarat-saratna panoembal teja, nja ijeu:

1. Di oenggal djoeroe, dihandapeun tatapakan, koedoe diroewangan tai beusi, bawang bodas djeung rĕrĕmĕkan 7 roepa, kajaning: rĕrĕmĕkan botol, piring, kĕndi, talawengkar, kĕnteng, bata, gotji atawa lian ti eta. Tai beusi watĕkna matak teuas kana taneuh, teu daekeun neundent, bawang bodas panjinglar kana 
dan de weg) terwijl de overkant (van den weg) daarmee op gelijke hoogte ligt; de aard van zulk een plek is, dat men door anderen overtroffen wordt. Als b.v. iemand die op zulk een plek een huis heeft gezet al rijk is, en daarna iemand (anders) aan den overkant van den weg een huis zet juist tegenover dat hetwelk in de laagte ligt, dan wordt dikwijls de persoon die in het lager gelegen huis woont arm of hij sterft, dat is, hij wordt overtroffen (moet wijken) voor den bewoner van het hooger gelegen huis.

$2^{\text {e }}$ "Lĕmah goenting", dat is grond die wordt ingesloten door de takken van een weg of van een rivier; zulk een plek brengt onheil aan.

$3^{\mathrm{e}}$ grond die naar het zuidoosten afloopt want, wel is waar leidt zulk een plek tot lust in het planten, maar (de aanplant) gelukt nooit.

$4^{\mathrm{e}}$ Grond die naar het Noord-westen afloopt wordt genoemd "anggon-anggon djaksa"; daar komen veel twisten voor.

$5^{\mathrm{e}}$ Grond die naar het Zuid-westen afloopt wordt genoemd "auggon-auggon doerdjana" en is dikwijls de verblijfplaats van boosdoeners.

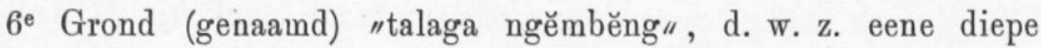
vallei, waar het water van de vier windstreken naar het midden stroomt en zich daar vereenigt, maar geene afwatering heeft en stilstaat; het effect daarvan is, dat er op zoo'n grond geen handel wordt gedreven.

7 Grond (genaamd "kantjah nangkoeb"), d. w. z. grond als een omgekeerde ijzeren pan; die is warm van aard, daar gaat alles op (kan men niets bewaren of besparen). De twee laatstbedoelde emplacementen worden als de slechtste beschouwd, bijna niemand gaat daarop wonen.

Het is niet voldoende een (goede) plek voor een huis te kiezen, die plek moet ook nog door bezweringsmiddelen gezuiverd worden. Vooral is dat een vereischte, (een voorschrift) voor grond waarop voor het eerst een huis wordt gezet.

De voorschriften betreffende (de aanwending) van die bezweringsmiddelen zijn de volgende:

$\mathrm{l}^{\mathrm{e}} \mathrm{Op}$ elken hoek moeten onder de neuten worden begraven: roest, witte uien en 7 soorten van scherven, zooals van flesschen, borden, gĕndi's, gebarsten of gebroken aarden potten, dakpannen, metselsteenen, aarden kruiken of andere. Roest maakt dat de aarde hard, stevig wordt, zoodat deze niet inzinkt; witte uien zijn een 
panjakit; ari rĕrĕmĕkan. toembal njingkirkeun dĕdĕmit noe aja didinja.

2. Lamoen tanahna katjida tiisna, eta koedoe diroewangan boengboe, ambeh djadi haneut. Mĕrĕnahkeunana imah oge koedoe diatoer; sabeunang-beunang toekangeun imah koedoe leuwih pandjang tibatan boeroewan, watĕkna soepaja bisa ngampihan rĕdjĕki, hartina reja anoe diampihan tinimbang anoe dikaloewarkeun ${ }^{11}$.

Samemeh imah diadĕgkeun oge, pinjanghareupeunana geus diatoer, karana njanghareupna imah teh aja atoeranana, noeroetkeun wĕwĕdalan anoe bogana; noe dipambrih, soepaja loeloes rahajoe, adoh 12 balahi parĕk rĕdjĕki, sapĕrti :

1. Anoe wĕwĕdalan di Ahad, koedoe njanghareup ngidoel, pantona ditĕngah-tĕngah.

2. Anoe di Sĕnen wĕwĕdalanana, njanghareupna koedoe ngaler, pantona sabeulah ti wetan.

3. Lamoen wĕwĕdalan di Salasa imahna koedoe njanghareup ngaler, pantona di tĕngah-tĕngah.

4. Anoe dilahirkeun di Rĕbo, njanghareupna koedoe ngidoel, pantona ditĕngah-tĕngah.

5. Dĕmi anoe di Kĕmis didjoeroekeunana, imahna koedoe njanghareup ngetan, pantona ti kidoel atawa ti kaler. Atawa njanghareupna mah ka kaler hade, ka kidoel hade, ngan pantona koedoe ti wetan.

6. Ari anoe wěwĕdalan di Djoemaäh njanghareupna koedoe ngoelon, pantona ti kaler atawa ti kidoel.

Lamoen imahna disanghareupkeun ngaler atawa ngidoel, pantona koedoe ti sabeulah koelon.

7. Oepama wěwĕdalan di Saptoe, imahna koedoe njanghareup ngidoel, pantona sabeulah ti wetan.

Alam ajeuna geus meh bijasa njanghareupkeun imah ka koelon atawa ka wetan soemawonua lamoen njanghareup ka djalan.

Ari baheula mah tara pisan aja imah njanghareup ngetan atawa ngoelon teh, sabab watěkna panas gĕringan; njanghareupna teh ngan ngaler djeung ngidoel bae, sanadjan di sisi djalan anoe 
middel tot verdrijving van ziekte en scherven zijn een bezweringsmiddel tegen de geesten, die zich daar ophouden.

$2^{\mathrm{e}}$ Als de grond zeer koud is, moet men er specerijen in begraven, opdat hij warm worde.

Ook de plaatsing (eig. de bepaling van de plaats voor het huis) moet volgens bepaalde gegevens geschieden; zoo mogelijk moet het achtererf langer zijn dan het voorerf, opdat er wat bewaard, overgespaard kunne worden, d. w. z., hetgeen wordt overgespaard is meer dan hetgeen wordt uitgegeven.

Vóórdat het huis gezet wordt, is reeds bepaald naar welken kant het front zal maken, want het front maken van het huis wordt bepaald met inachtneming van den geboortedag des eigenaars; men beoogt daarmee: voortdurend welzijn, bevrijd blijven van rampen en eene gemakkelijke kostwinning (voor den eigenaar van het huis).

$1^{\mathrm{e}}$ Het huis van iemand die op een Zondag geboren is, moet front maken naar het Zuiden en de deur moet in het midden zijn.

$2^{\text {e }}$ Indien de geboortedag van den eigenaar op een Maandag valt, moet het huis front maken naar het Noorden en de deur moet aan de Oostzijde zijn.

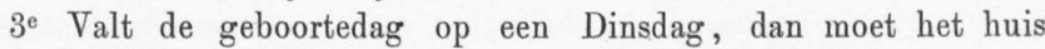
naar het Noorden front maken en de deur in het midden staan.

$4^{\text {e }}$ Wie op een Woensdag geboren is, moet zijn huis naar het Zuiden front laten maken en de deur moet in het middeu zijn.

$5^{\text {e }}$ Van iemand die op een Donderdag geboren is, moet het huis naar het Oosten front maken en de deur in de Zuidelijke of Noordelijke wand worden aangebracht.

Het huis mag ook naar het Noorden of het Zuiden front maken, maar dan moet de deur aan de Oostzijde zijn.

$6^{\text {e }}$ Van iemand die op een Vrijdag geboren is, moet het huis naar het Westen front maken en de deur aan de Zuidzijde worden aangebracht. Als men het huis naar het Noorden of naar het Zuiden front laat maken, dan moet de deur aan de Westzijde zijn.

7e Van iemand die op een Zaterdag geboren is, moet het huis naar het Zuiden front maken en de deur aan de Oostzijde zijn.

Tegenwoordig is men al bijna gewend om het huis naar het Oosten front te laten maken, vooral wanneer het (dientengevolge) met de voorzijde naar den weg komt te staan.

Vroeger waren er in het geheel geen huizen die front makten naar het Oosten of het Westen, omdat daardoor ziekten ontstonden, 
ngoedjoer ngaler oge.

\section{Ti ngadĕgkeun nĕpi ka anggeusna.}

Oepama geus diatoer pitĕmpateunana djeung pinjanghareupeunana kitoe deui toembal-toembalna sadija, teu aja noe kaliwat, toeloej milih powe anoe hade pikeun ngadĕgkeun.

Dĕmi powe anoe hade teja pikeun ngadĕgkeun imah, nja eta powe Ahad, sabab goesti Allah oge ngadamĕlna boemi langit mimitina powe eta. Tatapi kitoe oge koedoe milih Ahad anoe aloes.

Piisoekaneun ngadĕgkeun, di tĕngah-tĕngah lahan anoe rek diimahan teja didjijeunan lombang.

Ti peutingna diseungeutan damar, singsimna toedjoeh, diteundeun di djĕro lombang teja.

Eta damar koedoe dikanjahokeun dělěs mana anoe pangheulana pareum.

Oepama anoe pangheulana pareum teh, dĕlĕs noe njanghareup ngaler, djadi sabeulah ti kaler koedoe diroewangan deui rĕrĕmĕkan toedjoeh roepa, tjara noe ĕnggeus, sabab maksoedna eta damar noedoehkeun beulah ti mana anoe aja keneh děděmitna.

Isoekna, dina waktoe rek ngadĕgkeun teja, damar ditjokot diganti dipĕlakan anak tjaoe manggala djeung djawer kotok.

Dĕmi kasiatna boros tjaoe manggala matak awet dijaja noe ngeusian, djawer kotok, watěkna tara roentag.

Kadjaba ti boros tjaoe manggala djeung djawer kotok, deukeut lombang teh koedoe disadijaän tjibejas dina djadjambaran. Barang rek prak ngadĕgkeun, koedoe adan heula djeung matja doä salamĕt.

Sanggeus ngadĕg koedoe meuntjit hajam, getihna dikoetjoerkeun kana lombang teja, djeung gĕtih noe aja keneh dina beuheungna koedoe dioelas-aleskeun kana tihang. Eta hajam minangka parepeh, maksoedna noe matak gĕtihna dikoetjoerkeun kana lombang, soepaja 
de huizen waren slechts gericht naar het Noorden of het Zuiden, zelfs (al stonden zij) aan den kant van den weg, die recht naar het Noorden liep.

\section{Van het oprichten tot aan de voltooiïng.}

Als de plaats waar het huis gebouwd en de zijde waarnaar het front zal maken reeds bepaald en bovendien de bezweringsmiddelen gereed zijn en niets vergeten is, dan kiest men den voor het bouwen van het huis geschikten dag.

De dag die goed is om het huis te bouwen (d. w. z. er mee te beginnen) is de Zondag, omdat God met het scheppen van aarde en hemel op dien dag is begonnen. Men moet echter een goeden Zondag kiezen.

Als men morgen zal bouwen (dus op den dag voordat men begint te bouwen) wordt midden in den grond waarop het huis zal gebouwd worden een kuil gegraven.

Des avonds wordt een lampje aangestoken met 7 pitten en in dien kuil gezet. •

Van die lamp moet men maken dat men weet (dus: moet men nagaan) welke pit het eerst uitgaat.

Als b.v. de pit die het eerst uitgaat de naar het Noorden gerichte is, dan moet men aan de Noordzijde weer 7 soorten van scherven begraven, zooals die welke reeds (begraven zijn), want de bedoeling van die lichtjes is, aan te wijzen, aan welken kant zich nog geesten bevinden.

Den volgenden dag wanneer men wil gaan bouwen, neemt men de lamp weg en plant pisang manggala en djawer kotok (hanekam) in den kuil (waarin de lamp heeft gestaan).

Het effect van het binnenste van den pisang manggalaboom is, dat de bewoner van het huis lang zal leven en gezond en krachtig zijn, van de djawer kotok, dat het huis nooit zal instorten.

Behalve het binnenste van de pisang manggala en djawer kotok moet dicht bij den kuil rijstwater worden klaargezet in een groote aarden kom.

Als men met bouwen wil beginnen moeten eerst de adan (de aankondiging van het gebed) en de doä salamet uitgesproken worden.

Wanneer de stijlen al staan moet men een kip slachten en het bloed van die kip in den kuil laten vloeien, terwijl het bloed dat 
noe ngeusian oelah bidjil gĕtih, tĕgĕsna meunang tjilaka nĕpi ka bidjil gĕtih.

Ari noe matak dioelas-aleskeun kana tihang, soepaja anoe migawe eta imah oelah bidjil gĕtih.

Geus kitoe eta lombang ditjitjian deui tjibejas noe beunang njadijakeun tadi teja, kasiatna, soepaja noe ngeusian oelah kakoerangan bejas.

Dĕmi sanggeus ngadĕg, pabidähan anoe dianggo nja eta:

1. Bilangan rejana daroeroeng, lamoen dibagi opat koedoe njesa doewa. Anoe matak koedoe dibagi opat, noeroetkeun bingbilangan: so eroeng, sarang, wangke, wangkong.

Eta bingbilangan noe opat pada aja karĕpna.

Soeroeng karĕpna kasoeroeng koe napsoe, tĕgĕsna tatjan lila ditjitjinganana kaboeroe didjoewal atawa ditinggalkeun.

Sarang hartina njarang sagala balahi, nja ijeu bingbilangan anoe hade.

W angke tĕgěsna bangke, karĕpna eta imah weuteuh keneh, geus dipake noe hilang.

W angkong tĕgĕsna ngawangkong atawa ngawadoel, watĕkna eta imah sok dipake ngawangkong. ${ }^{13}$

Ari ngitoengna dina sesana ngabagi koe opat teja:

Oepama sesana hidji ninggang di soeroeng watĕkna goreng, sakoemaha noe geus disěboet di loehoer.

Lamoen njesa doewa, ninggang di sarang, watěkna hade djeung satoeloejna.

Eta sababna noe matak sesana ngabagi koedoe doewa teh, soepaja ninggang di sarang.

Bingbilangan bahas hĕnteu aja katangtoeanana, koemaha meudjeuhnana bae, ngan di lĕbah ĕnggon koedoe aja bahas noe ditangkarakkeun, kasiatna tara keuna koe sirĕp. 
daarna nog in den strot is (achtergebleven), op verschillende plaatsen aan de stijlen gesmeerd wordt. Die kip dient als bezweringsmiddel en de reden waarom men het bloed in den kuil doet vloeien is, dat het bloed van de bewoners niet worde gestort, m. a. w. dat hun geen ongeluk moge treffen waarbij het tot bloedstorting komt, en men smeert (bloed) aan de stijlen, opdat het bloed van de personen die het huis bouwen niet worde gestort.

Daarna wordt de kuil begoten met rijstwater, dat reeds van te voren was gereed gemakt (en wel), opdat de bewoners geen gebrek aan rijst zouden hebben.

Wanneer (de stijlen) reeds staan, worden de volgende bijgeloovige gebruiken in acht genomen:

$1^{\text {e }}$ Als men het getal, dat het aantal daroeroengs (de heele bamboe's waarop de vloer rust) aangeeft door 4 deelt, moet er 2 overblijven.

Het gedeeld worden door 4 staat in verband met de (vier) getallen (eig. speciale getalnamen): soeroeng, sarang, wangke en wangkong. Die getalnamen hebben hunne bedoeling. Soeroeng beteekent dat men door hartstochten, begeerte zal worden voortgedreven, m. a. w. dat niet lang na het betrekken van het huis, dit zal worden verkocht of verlaten.

Sarang beteekent verdrijven van alle rampen, dat is (dus) een gelukkig getal.

W angke of bangke duidt aan dat het huis, terwijl het nog nieuw is, door een lijk zal worden gebruikt (m. a. w. dat er spoedig iemand in zal sterven).

W angkong beteekent babbelen of kletsen en dat duidt aan, dat het huis dikwijls zal worden gebruikt om te babbelen of te kletsen (m. a. w. dat het druk bezocht zal worden).

De berekening van het overschot der deeling door 4. (geschiedt als volgt). Als de rest 1 is en dus op soeroeng valt, dat is slecht, zooals hierboven reeds is gezegd.

Als er 2 overblijft komt men bij het deelen (of liever bij het aftellen) op sarang, wat een goed teeken is enz.

Daarom moet de rest der deeling 2 zijn, opdat (bij het aftellen der daroeroengs), de laatste op sarang valle.

Voor de bahas (de vloerlatten op de daroeroeng's) zijn geene bepaalde getallen vastgesteld (die neemt men maar) zooals dat het beste uitkomt, alleen moeten de bahas op de plaats waar het bed komt te staan, met de holle zijaln naar fím 
Alam ajenna mah djangkoengna imah, gĕdena panto, geus beda pisan djeung djaman baheula, da baheula mah kabeh oge aja bingbilanganana. Ari oekoeranana mah kaki atawa dim bae, ngan bilanganana aja atoeranana, saperti bilangan pandjangna tihang koedoe tjịplěs dibagi gèněp, nja eta nouroetkeun bingbilangan Sĕri katampeujan, roh kala, katiban kala, oendang lajoean, soegih moekti, beurat beunghar. Ari ngitoengua tjara tadi bae, noeroetkeun sesana ngabagi.

Lamoen tijiplës ninggang dina bingbilangan be u rat be u $\mathrm{nghar}$, nja eta noe pangaloesna, sabab bingbilangan noe bijeu teh gěněpanana pada mawa karĕp sapěrti: lamoen njesa hidji, ninggang dina 8 ëri $\mathrm{katampeujan}$, watëkna sok kadjongdjonan, ${ }^{14}$ sanadjan teu boga bejas atawa balandja oge, ngeunah-ngeunah bae, hĕnteu daek balangsijar.

Njesa doewa ninggang dina roh kala, watĕkna gerringan.

Njesa tiloe ninggang dina bingbilangan katiban kala ${ }^{15}$, pĕrbawana sok oenggah bale watangan ${ }^{16}$. Lamoen njesa lima eta hade ${ }^{17}$.

$\mathrm{Nja}$ kitoe deui roebakna panto koedoe noeroetkeun bingbilangan noe bijeu, ngan djangkoengna geus pasti koedoe sahibas tjeuli, sabab pĕrbawana lamoen aja bangsat asoep, tangtoe lěbah panto kadenge rĕketna koe noe boga imah, masih keur hëes oge.

Oerang dijeu mah ana njijeun imah, powejan ngadĕgkeun oge sok nĕpi ka tĕrap soehoenan. Oepama geus tĕrap eta, koedoe maen rĕboetan, atoeranana kijeu.

Eta imah dikoebĕng koe rara atawa tali lian ti eta, digantoengan 
door zullen toovermiddelen om iemand in slaap te maken nooit effect hebben (op de personen die daar slapen).

Ten opzichte van hunne hoogte en de grootte der deuren verschillen de huizen die thans gebouwd worden aanmerkelijk van die van vroeger, omdat daarvoor toen eene bepaalde berekening werd in acht genomen.

De maten (die men bezigde) waren voeten en duimen, maar het aantal (voeten en duimen) moest aan zekere voorwaarden voldoen. Zoo moest b.v. het getal dat de lengte (hoogte) der stijlen aangaf deelbaar zijn door zes en zulks in overeenstemming met de getalnamen: Sĕri katampeujan enz. (zie Soend. tekst).

De berekening geschiedde als zooeven (is uitgelegd) met inachtneming van het overschot der deeling.

Als de deeling opging en men dus bij de aftelling kwam op den getalnaam beurat beunghar, dan was dat het beste. Want de zooeven genoemde getalnamen hebben alle zes hunne bedoeling b.v.: als er één overschoot kwam men (bij de aftelling) op sěri $\mathrm{k}$ atampeujan, dan was dat een teeken dat de bewoners onverschillig, lui zouden worden en al hadden zij geen rijst of geld, maar kalm met de handen in den schoot zouden blijven zitten en er niet op uit zouden willen gaan om den kost te verdienen.

Als er 2 overschoot dan kwam men (bij het aftellen) op roh $\mathrm{kala}$ en dat was een teeken dat er veel of dikwijls zieken in huis zouden zijn.

Bleef er 3 over, dan kwam men op katiban kala en dat beteekende dat de bewoners de landraadzaal (paseban) zouden binnengaan, (m. a. w. dat zij dikwijls met politie en justitie te doen zouden hebben).

Als er 5 overbleef, dat was goed (want dan kwam men bij het aftellen op soegih moekti d.i. rijk).

Evenzoo was de breedte van de deur afhankelijk van de zooeven genoemde getalnamen, maar de deur moest in elk geval zoo hoog zijn als de ooren (van een rechtopstaand volwassen mensch) want het effect daarvan is, dat wanneer boosdoeners (het huis) binnengaan er zeker door den eigenaar, ook al sliep deze, gekraak zou worden gehoord in de buurt van de deur.

Wanneer de menschen van hier een huis bouwen, plaatsen zij dikwijls den nokbalk op den dag waarop het huis wordt opgericht (d. w. z. de stijlen).

Als die nokbalk reeds op zijn plaats is gebracht, dan moet er via free access 
warna-warna kadaharan kajaning: koepat, tangtang-angin ${ }^{18}$, opak ${ }^{19}$, borondong ${ }^{20}$, dodol ${ }^{2}$, wadjit ${ }^{2} 2$ djeung lian ti eta, sarta di oenggal djoeroe dina tihangna digantoengan tjaoe toeroejan djeung tiwoe leundjeuran.

Ari dina soehoenanana diteundeunan pare, kalapa, papakean djeung warna-warna kadaharan tjara di handap.

Dimana geus ngadoä, gĕr pada mĕrĕboetkeun koe noe digarawe djeung koe bararoedak kadaharan noe dihandap djeung noe di loehoer teh; ngan pare djeung papakean hĕnteu. Parena diampihkeun ka leuit, didjijeun djimat pamikat pare, papakeanana diteundeun.

Ari noe matak make atoeran maen rĕboetan sarta di soehoenan diteundeunan pare djeung papakean, eta maksoedna soepaja noe boga imah oelah kakoerangan rĕdjĕki, saroepaning papakean, pare djeung kadaharan.

Satoengtoeng imah keur rangkaj keneh, koedoe bae diseungeutan damar ti peuting, soepaja noe bogana tjaäng pikirna tĕgĕsna euweuh kasoesah, djeung ambeh oelah diĕnggonan djoerig.

\section{Pindah.}

Samemeh imah anggeus pisan, sapĕrti kari njĕmpedanana, atawa kari ngagolodogan, eta imah koedoe geuwat dipindahan, sabab lamoen dipindihan geus anggeus pisan, pĕrbawana matak ngĕdoel ka noe ngeusian.

Di oenggal djoeroe eta imah koedoe diteundeunan kele pinoeh koe tjai, tapi kelena oelah di dengdeng.

Ari waktoena pindah koedoe milih powe noe hade djeung koedoe powe wĕwĕdalan manehna atawa pamadjikanana. Dĕmi parabotna anoe barĕng djeung djĕlĕmana dibawa pindah, nja eta: 1 samak anggĕl, 2 pabejasan, 3 tjai, 4 lěboe.

Anoe matak eta noe 4 perrkara didjijeun loeloegoena parabot pindah, sabab sagala djĕlĕma hĕnteu meunang tinggal tidinja: samak anggĕl pikeun sare, pabejasan noe ngahoeripkeun, tjai pon nja kitoe keneh, ari lĕboe minangka hawoena, sanadjan aja bejas, oepama taja hawoe mowal djadi sangoe. 
rĕboetan worden gehouden op de volgende wijze. Om het huis heen wordt bindgaren of een ander soort touw gespannen en daaraan worden allerlei spijzen gehangen zooals: kĕtoepat, tangtang-angin, opak, borondong, dodol, wadjit enz. en op elke hoek (van het huis) worden de stijlen behangen met pisang in trossen en heele stengels suikerriet.

Op de nok legt (hangt) men padi, klappers, kleeren en allerlei spijzen, zooals die welke beneden (zijn opgehangen).

Als er gebeden is wordt er gevochten, gegrabbeld door de werklieden en de jeugd, om de eetwaren beneden en boven, alleen niet om de padi en de kleeren. De padi wordt opgeborgen in de rijstschuur en gebruikt als djimat om rijst te lokken, de kleeren worden opgeborgen.

Die rěboetan wordt gehouden en de nok met padi en kleeren belegd, opdat de eigenaar van het huis geen gebrek zal hebben aan het noodige, zooals kleeren, rijst en (andere) spijzen.

Tot aan het einde van den tijd dat het huis nog niet af is, moet 's avonds damar worden gebrand, opdat de eigenaar er van aangename gedachten, d. w. z. geen zorg zal hebben en (tevens) opdat het niet door booze geesten zal worden bewoond.

\section{Verhuizen.}

Vóórdat het huis geheel af is; b.v. wanneer alleen de latten nog aangebracht moeten worden om de bilik vast te zetten of alleen het maken van een stoep (trap) nog overblijft (te doen), moet men er spoedig in verhuizen (er in gaan wonen), want wanneer men dit doet als het geheel klaar is, dan zal dat oorzaak zijn dat de bewoners lui worden.

In elken hoek van het huis moet men een bamboe met water gevuld plaatsen, maar deze mag niet recht afgesneden worden.

Voor het tijdstip van het verhuizen moet men een goeden dag kiezen en het moet de geboortedag zijn van den eigenaar of van zijne vrouw.

De zaken die de menschen bij het, verhuizen meebrengen zijn: $1^{\mathrm{e}}$ matje en hoofdkussen, $2^{\mathrm{e}}$ de rijstmand, $3^{\mathrm{e}}$ water, $4^{\mathrm{e}}$ asch.

De reden waarom die vier zaken als de voornaamste worden beschouwd, die men bij het verhuizen moet overbrengen is, omdat niemand het kan stellen zonder een matje en een hoofdkussen om te slapen, de pabejasan (n.l. de rijst daarin) noodig om te leven 
Kadjaba tidinja eta lěboe aja deui kasiatna, nja eta mawa pangabĕtah anoe pindah tina imah atawa ririboeg anoe ditinggalkeun ka imah noe dipindahan, soepaja oelah ngarasa teu bětah dina imah weuteuh.

Sanggeus boes asoep kadjĕro eta imah, lĕbe atawa doekoen koedoe matja doä di oenggal djoeroe, njingkahkeun djoerig noe njoempoet didinja, djeung njinglar, soepaja oelah kadatangan djoerig ti tĕmpat sedjen.

Tidinja toeloej njalamětkeun.

Njijeunna ĕnggon oge aja atoeranana tjara njanghareupkeun imah teja, noeroetkeun wěwĕdalan anoe bogana.

1. Anoe wĕwĕdalan di Ahad lamoen ngora keneh, njijeunna ĕnggon koedoe ti wetan modjok ngidoel; oepama geus kolot, ti koelon modjok ngidoel.

2. Lamoen wĕwĕdalan di Sĕnen, ĕnggonna koedoe ti koelon modjok ngidoel.

3. Oepama di Salasa, tjara di Ahad, ngan modjokna koedoe ngaler.

4. Anoe wĕwĕdalan di Rĕbo ĕnggonna koedoe ti wetan, modjok ngaler.

5. Ari noe di Kĕmis koedoe ti koelon.

6. Noe di Djoemaäh ti wetan.

7. Anoe di Saptoe koedoe ti koelon.

\section{Bab pabidähan dina pĕrkara imah-imah.}

Moenggoeh bangsa Soenda anoe katjida pisan pĕrtjajana kana adat adat karoehoen, nĕpi ka djadi koelit djadi daging salawasna imah-imah, hĕnteu pisan aja kĕndatna mĕtakeun pamake noe ĕnggeus ditĕtĕpkeun koe karoehoenna, anoe dipalar taja lian kadjaba ti hajang loeloes rahajoe, adoh balahi, parěk rĕdjěki. 
zoo ook water, en de asch vervangt de stookplaats. Al heeft men (ongekookte) rijst, als er geen stookplaats is, zal de bejas geen sangoe (gekookte rijst) worden.

Behalve dat heeft die asch nog een andere kracht, n.l. om te maken dat degene die verhuist, van het huis of de tijdelijke woning die verlaten wordt, het gevoel van op zijn gemak zijn meeneemt (en dus wordt asch meegebracht), opdat men zich in het nieuwe huis niet "onlekker" zou gevoelen.

Nadat men het huis is binnengegaan, moet de lĕbe (priester) of doekoen in elken hoek (van het huis) een gebed opzeggen, om de booze geesten die zich daar verschuilen te verdrijven en bezweringsmiddelen aanwenden (djampe's lezen, sirih spuwen of i. d.), opdat het huis niet worde bezocht door booze geesten van elders.

Vervolgens wordt een offermaaltijd (salamětan, siděkah) gehouden.

Het maken van de slaapplaats is ook aan regels onderworpen, zooals het richten van het huis, dat is n.l. af hankelijk van den geboortedag des eigenaars.

$1^{\text {e }}$ Als hij op een Zondag geboren en nog jong is, moet de slaapplaats aan de Oostzijde worden gemaakt in den Zuidelijken hoek, als hij al oud is aan de Westzijde en (ook) in den Zuidelijken hoek.

$2^{\mathrm{e}} \mathrm{Als}$ hij geboren is op een Maandag dan moet de slaapplaats zijn in den Zuidelijken hoek, aan de Westzijde.

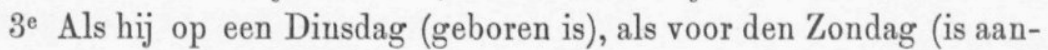
gegeven) maar dan moet de slaapplaats in den Noordelijken hoek zijn.

4. Die op een Woensdag geboren is moet zijne slaapplaats hebben in den noordoostelijken hoek.

$5^{\text {e }}$ Die op een Donderdag (geboren is) aan de Westzijde.

$6^{\text {e }}$ Die op een Vrijdag, aan de Oostzijde en

$7^{\mathrm{e}}$ die op een Zaterdag, aan de Westzijde.

\section{Over bijgeloof betrekking hebbende op het wonen (in huizen).}

De Soendaneezen die zoo sterk gelooven (gehecht zijn) aan de instellingen en gebruiken van hunne voorouders, zoodat deze bij hen (als het ware) vleesch en bloed worden zoolang zij in een huis wonen, beoogen met het inachtnemen van de door bunne voorouders vastgestelde regelen niets anders, dan (verzekering van) bestendigen voorspoed, verwijdering van gevaren en voldoende levensonderhoud. 
Oepama aja boedak anoe ngalampahkeun salah sahidjina tjĕgahna karoehoen teja, teu kira-kira digeunggeureuhkeunana djeung ditjaritakeun pitĕmaheunana, noe matak baroedak ajeuna bisa njaho kana eta tjĕgahan sawareh-wareheun.

Ijeu di handap ditjaritakeun hidji doewa panganggo sĕpoeh dina pĕrkara imah-imah anoe meh sarereja pada tĕrang.

1. Oelah sasapoe ti peuting soemawonna malĕm Djoemaäh djeung Salasa, hade oge sasapoe lamoen katjida pĕrloena, tapi roentahna koedoe digoendoekkeun didinja bae, sababna sok kaloewar rĕdjĕki tanpa poerwa.

2. Oelah mitjeun roentah powe Djoemaäh atawa Salasa, sababna tjara noe bijeu.

3. Oelah ngala tjai magrib (sareupna) sabab sok ditoetoerkeun bontjeret. ${ }^{2} 3$

Ari bontjeret teja nja eta keujeup bodas. Anoe matak noetoerkeun, njoesoel anakna leungit, soegan kabawa koe noe ngala tjai Ari anakna nja eta keujeup lĕmboet anoe beureum.

Eta bontjeret tjitjing bae dina bilik atawa dina panto, bari disada. Lamoen kadenge koe noe boga imah, toeloej moerakeun tjai ka panto bari diparantjahan kijeu: "Hih, aing mah teu ka tjai ti peuting, teu manawa anak sija! Toeh diditoe di imah kaler anoe ngala tjai teh!" Eta djĕlěma noedoehkeunana ka těmpat noe teu aja imahan. Lamoen noe taja imahan teh sabeulah kidoel, noedoehkeunana ka kidoel, djeung satoeloejna.

Eta bontjeret ana geus diparantjahan kitoe, sok toeloej njingkah.

4. Oelah ngadekan tihang sok katoeding teu boga dosa.

5. Oelah kakadekan dina bangbaroeng soemawonnna ngadekan bangbaroengna, matak oenggah bale watangan.

6. Oelah dijoek dina bangbaroeng atawa ngalong panto, matak nongtot djodo.

7. Oelah ngesedkeun ${ }^{24}$ soekoe kana sapoe panjaraän, matak rorombeheun.

8. Oelah njidoeh di parako. 
Als een kind een van de verbodsbepalingen van de voorouders overtreedt dan wordt hij zeer streng berispt en hem verteld wat het gevolg daarvan zal zijn; daarom kennen de kinderen thans (eig. zij die thans kind zijn) gedeeltelijk die verbodsbepalingen.

Hieronder worden enkele voorouderlijke gebruiken vermeld, betrekking hebbende op het wonen, welke aan bijna iedereen bekend zijn.

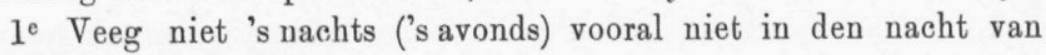
Donderdag op Vrijdag en van Maandag op Dinsdag. Het is wel goed te vegen (men mag dan wel vegen) als dat erg noodig is, maar (de aangeveegde) vuilnis moet daar (nl. in huis) op een hoop worden geveegd, omdat men (anders) nuttelooze uitgaven doet.

$2^{\text {e }}$ Werp geen vuilnis weg des Vrijdags om de zooeven vermelde reden.

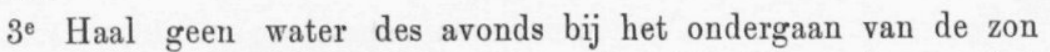
(als het donker wordt), omdat men dan dikwijls wordt vervolgd door een bontjeret.

Een bontjeret is een kleine witte keujeup (rivierkrab). De reden waarom hij vervolgt, is, dat hij zijn jong naloopt, dat misschien meegenomeu is door de persoon die water haalt. Zijn jong is een kleine roode keujeup.

Die bontjeret zit in den wand of in het hout van de deur en geeft geluid. Als dat gehoord wordt door den eigenaar van het huis, dan spuwt hij (zij) water naar de deur en spreekt het volgende bezweringsformulier uit:

"Ik ben vanavond niet naar de rivier gegaan en ik heb je kind niet meegenomen. Daar, ginds in dat huis ten Noorden, daar is de persoon die water heeft gehaald". Tegelijkertijd wijst hij naar het Noorden waar geen huizen zijn. Als er geen huizen zijn naar de Zuidzijde, dan wijst hij naar het Zuiden enz.

Als die bontjeret al op die wijze bezworen is, gat hij meestal dadelijk heen.

$4^{\text {e }}$ Hak niet in de stijlen (van het huis) dan wordt men dikwijls belasterd zonder schuld te hebben.

$5^{\text {e }}$ Hak niet (spelenderwijs en bij herhaling) op den drempel en hak er vooral niet in, dat geeft aanleiding tot "perkara's."

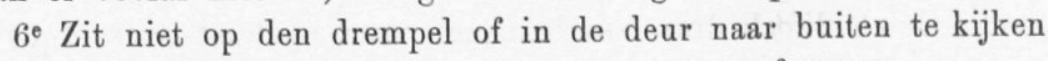
(zonder iets te doen) dan krijgt men geen man of vrouw.

7 V Veeg uwe voeten niet af an een bezem van padistengels, dan krijgt men kloven of barsteu in de zool van den voet.

$8^{e}$ Spuw niet op de stookplaats. 
9. Oelah paseja djeung pamadjikan ti peuting.

10. Oelah ngěboetkeun boeöek di ĕnggon.

Ijeu larangan noe 4 pangpandeurina, matak di sapa koe $\mathrm{Nji}$ Sri. 25

11. Oelah ngala seuneu lamoen di hawoe oerang aja seuneu, matak gĕring panas.

12. Oelah ngomong djeung pamadjikan di ĕnggon, matak paseja.

13. Oelah sisijaran di ĕnggon, matak galak paseja.

14. Oelah sok hehejotan di imah, matak teu boga oejah.

15. Oelah marinan tjai tina kĕndi kana kĕndi deui, matak tjerewed mitoha.

16. Oelah nakol seëng, matak reja semah.

17. Oelah neundeun hoeroenan soeloeh di imah, matak dihoeroensoeloehkeun, 29 tĕgĕsna kabaoed pĕrkara.

18. Oelah nangtoengkeun goeloengan samak, matak ririwit boedak.

19. Oelah bra-broe papakean, matak gĕring sa-imah-imah.

20. Oelah noeroeban bejas atawa kedjo koe ajakan, sabab katjadoena Nji Sri.

21. Ari njijoek bejas oelah bari ngomong, matak longlongan ${ }^{27}$.

22. Ari njijoek bejas ti pabejasan koedoe mĕpĕt bajoe tiloe kali, tĕgěsna bari njijoek bejas, noe tiloe kali pangheulana oelah ngamběkan, bari diparantjahan kijeu: "Noe herang noe ngalenggang noe ngagentjlang, mahal sorangan" ${ }^{28}$ Ijeu kasijatna soepaja oelah longlongan.

23. Nja kitoe deui lamoen asoep ka leuit aja pamakena, koedoe ngoelaskeun minjak kalapa kana ĕmboen-ĕmboenan tiloe kali, toeloej diparantjahan kijeu, "Sangratoe tjokot, oelah satjokot-tjokotna, dagoan pamere aing," 29 Ijeu oge karepna soepaja oelah longlongan.

24. Oepama ngaleuseuhan hawoe oelah njĕboet "euweuh", matak malarat.

25. Lamoen dahar, sangoena beunang njangoe dina hawoe weuteuh, papatjoewan oelah dek ngadjak dahar ka batoer, koedoe toengkoel bae, soepaja beunghar. 
$9^{\text {e }}$ Twist des avonds niet met uwe vrouw.

$10^{\mathrm{e}}$ Schud uw haar niet uit op de slaapplaats.

Door overtreding van de laatste vier verbodsbepalingen wekt men den toorn op van Nji Sri (eig. wordt men vervloekt door N. S.).

$11^{\mathrm{e}}$ Haal geen vuur van elders, als er in de eigen stookplaats vuur is, dat veroorzaakt koorts.

$12^{\mathrm{e}}$ Spreek niet met uwe vrouw op de slaapplaats, dat geeft aanleiding tot twist.

$13^{\mathrm{e}}$ Luis (elkaar) niet op de slaapplaats, dat veroorzaakt hevige twist.

14 e Fluit niet (met den mond) in huis, dat zal oorzaak zijn dat men geen zout heeft.

$15^{\mathrm{e}}$ Schenk geen water uit de eene gĕndi in de andere over, dat geeft onaangenaamheden met de schoonouders.

$16^{\mathrm{e}}$ Sla niet op de seëng (koperen pot), daardoor zouden veel gasten komen.

17e Leg geen bos brandhout in huis, anders wordt men dihoeroensoeloehkeun d. w. z. in pĕrkara's (van anderen) betrokken.

$18^{\mathrm{e}}$ Zet geen opgerolde mat overeind, dat geeft aanleiding tot ziekte van de kinderen.

$19^{\mathrm{e}}$ Gooi niet overal kleeren neer, dat geeft ziekte in huis.

20. Dek geen ongekookte of gekookte rijst met een zeef, want dat is door $\mathrm{Nji}$ Sri verboden.

$21^{\mathrm{e}}$ Als men ongekookte rijst opschept, mag men daarbij niet praten, want dan zal de rijst gauw op zijn.

$22^{\circ}$ Als men rijst opschept uit de pabejasan, dan moet men drie maal den adem inhouden, d. w. z. terwijl men de eerste drie keeren opschept mag men niet ademhalen en moet men het volgende bezweringsformulier uitspreken ... ${ }^{28}$ De kracht daarvan is, dat de rijst niet gauw op gaat.

$23^{\mathrm{e}}$ Ook is het een gebruik dat men bij het binnentreden van de rijstschuur driemaal klapperolie op den kruin (van het hoofd) smeert en daarna het volgende bezweringsformulier uitspreekt: $\ldots \ldots \ldots{ }^{29}$ Daarvan is eveneens de bedoeling dat de rijst niet spoedig verbruikt moge zijn.

$24^{\mathrm{e}}$ Als men eene nieuwe stookplaats in gebruik stelt, dan moet men het woord "euweuh" (er is niet) niet uitspreken, want dat zou oorzaak zijn van armoede.

$25^{\text {e }}$ Als men de rijst eet die op eene nieuwe stookplaats is gekookt, moet men vooral geen andere menschen uitnoodigen om er van te eten, men moet maar voor zich kijken, opdat men rijk worde. 
26. Oelah tjingogo di parako, matak heuntjeut oetjingeun.

27. Malĕm Djoemaäh koedoe ngoekoes sarta oelah pareum damar, djeung koedoe disadijakeun kĕndi beunang minoehan, seupaheun djeung roeroedjakan gonjokkeun deukeut damar di tĕngah imah, maksoedna njoegoeh $\mathrm{Nji}$ Sri.

Babakoena anoe sok ngalampahkeun kitoe teh, toekang tani anoe hajang dipikaäsih koe $\mathrm{Nji}$ Sri.

28. Oelah heës handapeun pangĕrĕt, matak ditoempakan koe eureup-eureup.

Aja oge hidji doewa djĕlĕma anoe njarita, jen manehna geus papanggih djeung eureup-eureup. Eta eureup-eureup teh djoerig, roepana djiga nini-nini hideung, babakoena tjitjingna dina pangěrĕt.

Oepaina aja noe sare handapeun pangerrĕt, toeloej toeroen noempakan, nĕpi ka teu bisaeun ngambĕkan noe sare teh.

29. Oelah heës nangkarak, matak ditoempakan djoerig.

30. Oelah sok njoö bejas, matak didjoewal koe towa.

31. Oelah sok lalanggiran, matak paeh indoeng.

32. Ari njitjikeun tji asak kana tjatjangkir oelah leber teuing, matak dikoelak deungeun, tĕgĕsna dioenghak batoer. 
$26^{\text {e }}$ Zit niet (gehurkt) op de stookplaats, anders wordt men licht zwanger (of als het een man is, diens vrouw).

27e Des Donderdags avonds moet men wierook branden, mag men de lamp niet uitblazen en moet men een gevulde kĕndi gereed zetten (zoomede) de benoodigdheden voor het sirih pruimen en verschillende soorten van roedjak rondom en dicht bij de lamp, met het doel om $\mathrm{Nji}$ Sri te onthalen.

Het zijn vooral de landbouwers, die de genegenheid van $\mathrm{Nji}$ Sri willen verwerven, welke zoo handelen.

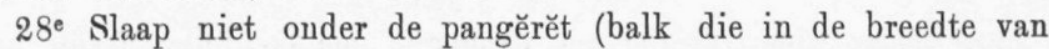
het huis op de stijlen ligt) daardoor krijgt men de nachtmerrie.

Er zijn enkele menschen, die vertellen dat zij een eureupeureup hebben ontmoet. Zoo'n eureup-eureup is een booze geest die er vitziet als een zwarte oude vrouw, die voornamelijk (in den regel) op de pangěrĕt zit.

Als nu iemand onder de pangěrĕt slaapt, dan komt zij naar beneden en gaat op de slapende zitten (zoodat) deze niet kan ademhalen.

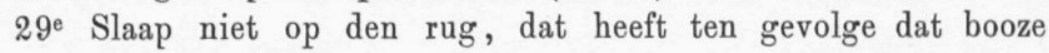
geesten op den slaper gaan zitten.

$30^{\mathrm{e}}$ Speel niet met rijst, anders wordt men verkocht door zijn oom (of tante).

$31^{\mathrm{e}} \mathrm{Ga}$ niet op den buik liggen met de beenen omhoog (langgir $=$ schorpioen), anders sterft uwe moeder.

$32^{\mathrm{e}}$ Als men gekookt water (of warm drinken; verg. tjianeut) in een kopje giet, mag men het niet te vol schenken, anders wordt men getergd, uitgedaagd, d. w. z. men zal onbeschoft behandeld, gebrutaliseerd worden. 


\section{A ANTEEK ENINGEN.}

1. pabidähan grw. bidäh (Ar. بد عت ), kettersch, ketterij; hĕnteu moepakat djeung sarä (C.).

2. watĕk volgens (O.): het vermogen van een tooverformulier, hier vermogen effect van de bijgeloovige handeling.

3. Kasiat (Ar. خاصية) heeft ongeveer dezelfde beteekenis als watĕk; volgens (C.) = pĕrbawa, welk woord in die beteekenis ook in dit stuk voorkomt.

4. roengsĕb (C.) niets dan graat zijn van kleine vischjes; volgens (O.) ook: zijn met uitstekende steenen, blootliggende wortels.

Soend.-Holl. Samenspr. van Holle en Karta Winata: blz. 47 "hĕnteu roengs ĕb didaharna" = geschikt om gegeten te worden; roengsĕb: ongeschikt daarvoor, door te veel graten.

roengsĕb pikirna: onaangenaam gestoorde gedachten, zorg, getob.

5. sarat (O.), middel, vereischte enz. (Ar. شر ط).

6. salamangsa en sagawajah, verkortingen van sagalamangsa en sagalawajah.

7. naäs of nahas = (Ar. نحسر).

8. ngagaloedra ngoepoek van galoedra of garoeda, draak, griffioen, i. h. a. groot fabelachtig dier en ngoepoek zich bakeren in het zand zooals een kip, nadat deze met pooten en vleugels daarvoor een kuil heeft gemaakt.

ngagaloedra ngoepoek wordt dus gezegd van een terrein, dat er uitziet alsof een groot dier daar in een kuil heeft gelegen.

9. kalindeukan van grw. lindeuk, mak, tam, beteekent: gewend zijn, zich op zijn gemak voelen of de plaats waar dat het geval is. 
10. ng ĕmbĕng: onder water zetten of, zooals hier: stilsta a n van water.

11. "reja anoe di ampihan enz."; de bedoeling zal wel zijn: opdat er meer ontvangen dan uitgegeven worde.

12. adoh (Jav.) $=$ djaoeh.

13. ngaw angkong, praten kletsen (O); Soend. Holl. Samenspr. van Holle en Karta Winata blz. $169 \mathrm{II}$ : "hajang noeloejkeun wangkongan kamari ijeu teja."

14. kadjongdjonan zie tonggoj; voortgaan, ook met niets doen, vandaar: indolent, onverschillig.

15. katiban van Jav. tibå? = vallen; katiban kala, getroffen, overvallen door rampen.

16. bale watangan eig. gebouw, zaal, waar gewogen wordt, nl. de schuld of onschuld van beklaagden.

17. oendang lajoean; omtrent de watĕkna van deze getalnaam wordt niets gezegd. De uitdrukking zal wel eene ongunstige beteekenis hebben, want oendang bet. wet, bevel, en lajoe, verkwijnen, verwelken.

18. tangtang-angin, rijst gekookt in driehoekig gevlochten bamboebladeren.

19. opak, broos, luchtig, bruin gebak van kĕtanmeel.

20. borondong, gerooste kĕtan tot ballen samengekleefd door gesmolten arensuiker.

21. dodol, soort van caramel mou, gemaakt van kĕtanmeel arensuiker en ingedroogde klappermelk.

22. wa ajit, koekjes gemaakt van kĕtan (heele korrels), overigens dezelfde bestanddeelen als dodol.

23. bontjeret, zie bĕntet $(\mathrm{O})$, "naam van een zeker insect dat zich 's nachts laat hooren. Het volgt meestal menschen die 'snachts naar de rivier of andere plaats daar water is zijn geweest, om hunne behoefte te doen en wel omdat, zooals het volksgeloof wil, zijn jongen, die in het water zouden leven, mee opgeschept werden bij het zich reinigen.

$\mathrm{Om}$ het insect te verjagen werpt men er veelal naar met een weinig water, onder het uitspreken van de woorden: tah 
anak sija" (daar heb je je kind). Deze lezing wijkt dus eenigszins af van hetgeen mij is meegedeeld.

24. ngesedkeun grw. kesed (Jav.)

25. $\mathrm{Nji}$ Sri of Dewi S ri, de bekende schutsgodin van de rijst. 26. dihoeroensoeloehkeun van hoeroen, samenbinden en s o eloe h, brandhout; dihoeroensoeloehkeun = als brandhout samengebonden en samen verbrand worden, of over één kam geschoren worden (O).

27. longlongan babari bejak (C).

28. "Noe herang noe ngalenggang noe ngagentjlang, mahal sorangan" bet. ongeveer: "gij blinkende, heldere, lichtende, gij zijt de allerbeste," en is een lofrede op de rijst.

29. "Sangratoe tjokot oelah satjokot-tjokotna dagoan pamere aing," is een verzoek, waarschijnlijk aan $\mathrm{Nji}$ Sri, om niet van de rijst te nemen, maar te wachten tot daarvan gegeven wordt. 